AJHSE Vol: 2 (1): 01-13, 2020

DOI.: 10.52417/ajhse.v2i1.119

Accepted Date: April 19, 2021

(C) 2021. CC License 4.0

www.ajhse.org

\title{
MISSED OPPORTUNITY FOR CHILDHOOD ROUTINE IMMUNIZATION IN BENIN CITY, EDO STATE, NIGERIA
}

\author{
*1'Uwaibi, N. E., \& ${ }^{2}$ Omozuwa, E. S. \\ ${ }^{*}$ Social Community Medicine Department, Edo university Iyamho, Edo State, Nigeria. \\ ${ }^{2}$ Department of Obstetrics and Gynaecology, Edo university Iyamho, Edo State, Nigeria \\ *Corresponding Author's E-mail: noel.uwaibi@gmail.com
}

\begin{abstract}
7 Expanded Program on Immunization (EPI) was created to scale up immunization of infants, but there have still been records of insufficient levels of immunization against childhood diseases in under-developed countries. Missed opportunity for vaccination is a strategy of achieving immunization coverage of at least $90 \%$ by reducing the process that facilitates it being missed and improving health service delivery in under-developed countries like Nigeria. The main objective of the study was to determine the level of missed opportunities in childhood routine immunization in Benin City, Edo State. A cross-sectional study design was utilized for this study in Primary Health Care facilities across the three Local Government areas in Benin city using a multistage sampling technique. The questionnaire was a pretested structured WHO tool, that was interviewer administered. Four hundred and seventyseven of the children were aged 5 months or less, $20.5 \%$ of the children were in the age bracket aged 6-11 months, while only 5 children were aged $18-23$ months $(0.8 \%)$. The mean age of the children was $4.2 \pm 3.5$ months. The mean age of the male children was $4.4 \pm 3.5$ months, while the mean age of the female was $3.9 \pm 3.2$ months. In conclusion, missed opportunity for vaccination in this study was high (16.1\%) and this can lead to increase in vaccine preventable diseases.
\end{abstract}

Keywords: childhood, diseases, healthcare, immunization, missed opportunities

LICENSE: This article by African Journal of Health, Safety and Environment (AJHSE)is licensed and published under the Creative Commons Attribution License 4.0 International License, which permits unrestricted use, distribution, and reproduction in any medium, provided this article is duly cited.

COPYRIGHT: The Author(s) completely retain the copyright of this published article.

OPEN ACCESS: The Author(s) approves that this article remains permanently online in the open access (OA) mode.

QA: This Article is published in line with "COPE (Committee on Publication Ethics) and PIE (Publication Integrity \& Ethics)". 


\section{INTRODUCTION}

The Expanded Program on Immunization (EPI) aims at delivering the primary immunization series to at least $90 \%$ of infants (Ireye et al., 2017). However, inadequate levels of immunization against childhood diseases remain a significant public health problem in under developed countries like Nigeria (Ekure et al, 2013). Most countries have established expanded immunization programs, and in developing countries, children under five years of age are immunized in accordance with the standard World Health Organization (WHO) recommended vaccines, that currently protect against eight diseases namely, tuberculosis, diphtheria, tetanus (including neonatal tetanus through immunization of mothers), Pertussis, Poliomyelitis, Measles, Hepatitis B, and Haemophilus Influenza) (Rouveaux et al., 2005).

Nigeria initiated the Expanded Programme on Immunization (EPI) in 1979, to ensure that all children had access to routinely recommended vaccines. This programme has led to significant progress in the delivery of immunization services with $81.5 \%$ coverage for all antigens recorded during the Universal Childhood Immunizations (UCI) days (1986-1990s) (Ekure et al., 2013).

The effectiveness of immunization programs in Nigeria is influenced by factors such as the coverage of the health network, missed opportunity for immunization, the existence and quality of immunization services, the quality of the cold chain, the liaison of communities with health services, the existence of population movement, and several other factors that are related to the vaccines in use, to health services or to communities. The relative effect of each aforementioned factor significantly varies according to geographical areas (Favin, 2012).

A missed opportunity for vaccination refers to any contact with health services by an individual (child or person of any age) who is eligible for vaccination, which does not result in the person receiving one or more of the vaccine doses for which he or she is eligible. It occurs in two major settings, during wellbeing clinics (growth monitoring, immunization, nutrition services) and during visits for curative services. Numerous health factors have been shown to contribute to missed opportunities; they include failure to assess immunization status of the child during such visits, failure to administer needed vaccines due to medical condition(s) erroneously perceived as contraindication, non-availability of vaccines, (Tagbo et al., 2014) failures by health care facilities to immunize on all days of the week, and negative parental attitudes and beliefs that prevent them from vaccinating the children.

National Programme on Immunization (NPI) prescribes five (5) visits to the health facility to receive one dose of Bacilli Calmette Guerin (BCG) and Hepatitis B at birth, three doses of Oral Polio Vaccine (including one IPV), and three doses of Pentavalent vaccine, at six, ten and fourteen weeks and one dose of measles vaccine and yellow fever given at nine months of age (FMOH, 2009: Scott et al., 2014). It is recommended that a child should receive all immunization at the appropriate ages and intervals to ensure maximal protection from vaccine preventable diseases (Adedire et al., 2016: Sadoh and Eregie, 2009). The percentage of children who have received the requisite number of vaccine doses irrespective of the age at receipt of the vaccine is used to determine vaccination coverage and the third dose of pentavalent vaccine is the key indicator to measure immunization programme coverage (Abdulkareem, 2011: Matua et al., 2016). Where accessibility and utilization of health services are low, every contact with a health facility provides an opportunity to immunize, particularly as these children are naturally at risk of vaccine preventable diseases (Tagbo, 2012). Considering naturally challenged immunity, current household food insecurity 
and unaffordable health care. Nigeria with its low coverage should leverage and capitalize on every opportunity where mother and child presents to PHCs for health services to carry out immunization activities (Erilesi, 1998).

Numerous reasons have been given for low routine immunization coverage, such as missed opportunities, late reporting for immunization, non- administration of simultaneous injections, and longer interval between pentavalent and measles vaccine (three and a half months) compared to that between the other vaccines in the schedule (four weeks) (Abdulkareem, 2011). Missed opportunities create gaps in the targeted herd immunity aimed at routine immunization and deaths from vaccine preventable diseases would continue to plague such societies. Thus, studying missed opportunities is paramount in up-scaling vaccination coverage and improving under five health indices. It is also anticipated that this study will help to discover reasons for missed immunisation opportunities, estimate the magnitude of this opportunity, help proffer solutions that will improve immunization coverage ultimately reduce childhood morbidity and mortalities due to VPDs, because if the diseases are not prevented it could affect the herd immunity of the community and lead to spread of diseases. The objective of this study was therefore to determine the level of missed opportunities in childhood routine immunization in Benin City with anticipation that this study will help to find out reasons for missed immunisation opportunities, and estimate the magnitude of these opportunities. It will thus help proffer solutions that will improve immunization coverage and ultimately reduce childhood morbidity and mortalities due to Vaccine Preventable Diseases. Improving childhood immunization coverage is critical on several systemic factors and underlying factors, one of which may be the mother not immunizing the child. This study will measure and determine immunization coverage in Benin City Primary Health Care (PHC) facilities and serve as a tool for policy makers, program implementers and immunization service providers during planning and evaluation and serve as a baseline for further studies.

\section{MATERIALS AND METHOD}

A total of 640 Mothers/child pair was recruited for the study from 35 PHC in the 3 local government areas in Edo state.15 This was determined using the Cochrane formula for studying single proportion (Cochrane, 1977) $n=(Z) 2 p q$ (deff)/ d2 using a prevalence of $51.0 \%$, which is the proportion of mothers dissatisfied with reception given by healthcare providers in a descriptive cross-sectional study conducted in 2010 in Calabar, Nigeria (Udonwa, 2010). And Adjusting for $10 \%$ non-response was done utilising the formula for non- response: $\mathrm{n} /(1-\mathrm{nrr})$ where nnr is (10\% or 0.1$)$.

Multistage sampling technique was used to select children included in the study. Included children $(0-23$ months old) brought to the primary health care centres during the study period for immunization (for other health services other than immunization) and who gave their consent.

\section{SAMPLING TECHINQUE}

Multistage sampling technique consisting of three stages was used in selecting the mothers /child pair. Mothers/caregivers were selected from the 3 LGA

Stage 1: Selection of Wards 
Two wards were selected from each of the 3 LGAs by simple random sampling, using balloting from the list of wards obtained from the PHC department in each LGA, making a total of 6 wards.

Stage 2: All the selected wards had one PHC each thus all the PHCs within the selected 6 wards were used for the study. Therefore 6 PHCs were selected for the study

Stage 3: Stratified sampling technique was used to select the mothers/caregivers. This was done in 2 steps.

Step 1: Allocation using probability proportional to size was done to obtain the sample size of mothers/caregivers that was selected from each of the selected PHCs.

A sampling fraction of 0.35 was estimated (Calculated sample size / Total monthly attendance for immunization in all selected PHC). This was used to allocate the number of mothers/caregivers to be selected from each of the 6 PHCs.

Step 2: Simple random sampling technique by balloting was then used to select the mothers/caregivers from each of the 6 PHCs using immunization register as the sampling frame, this was done until the sample size for each PHC was achieved. A structured interviewer administered questionnaire was used to collect data from mother/caregivers, using pretested WHO tool (methodology for the evaluation of missed opportunity for vaccination) ${ }^{1}$ was modified to collect information on immunization status and missed opportunity for vaccination. The questionnaire comprised of 3 sections:

SECTION A: Obtained information on the socio-demographic characteristics of the mothers/caregivers such as age, marital status, religion, ethnicity, and level of education.

SECTION B: Obtained information on the mother's/caregiver's knowledge of types of vaccine, purpose of immunization.

SECTION C: A WHO tool (methodology for the evaluation of missed opportunity for vaccination) (Sato, 1988) was modified to collect information on immunization status and missed opportunity for vaccination

\section{DATA ANALYSIS}

The questionnaires were screened for completeness by the researcher, coded and entered the IBM SPSS statistics 20.0 software. The categorical data were presented as frequencies and percentages while numerical data that were normal in distribution was expressed as mean (standard deviation). The Fisher's exact test was used in instances where the total expected cell frequencies less than five is more than $20 \%$. The binary logistic regression was modelled to explore and identify significant predictors of factors affecting immunization. The level of significance was set at $\mathrm{p}<0.05$.

\section{RESULTS}

Four hundred and seventy-seven (74.5\%) of the children were aged 5 months or less, 131 (20.5\%) of the children were in the age bracket aged 6-11 months, while only 5 children were aged 18-23 months ( $0.8 \%)$. The mean age (SD) of the children was $4.2 \pm(3.5)$ months. The mean age of the male children was $4.4 \pm 3.5$ months $(n=331)$ while the mean age of the female children was $(3.9 \pm 3.2)$ months $(n=309)$. There was no statistically significant difference between the means ages of both sexes (independent samples t-test with $\mathrm{p}$ value $=0.071$ ). Majority of the children, 497 
(77.7\%) were delivered in hospitals, followed by $120(18.8 \%)$ who were delivered at home while $23(3.6 \%)$ were in traditional birth attendants' homes. This is shown in table 1

Table 1: Socio-demographic characteristics of the children $N=640$

\begin{tabular}{|c|c|c|c|}
\hline Variable & Distribution & Frequency & Percent \\
\hline \multirow[t]{4}{*}{ Age (months) } & $0-5$ & 477 & 74.5 \\
\hline & $6-11$ & 131 & 20.5 \\
\hline & $12-17$ & 27 & 4.2 \\
\hline & $18-23$ & 5 & 0.8 \\
\hline \multirow[t]{2}{*}{ Gender } & Male & 331 & 51.7 \\
\hline & Female & 309 & 48.3 \\
\hline \multirow[t]{3}{*}{ Place of delivery } & Health facility & 497 & 77.7 \\
\hline & Home & 120 & 18.8 \\
\hline & TBA's home & 23 & 3.5 \\
\hline \multirow[t]{4}{*}{ Religion of parents } & Christianity & 604 & 94.4 \\
\hline & Islam & 27 & 4.2 \\
\hline & ATR & 6 & 0.9 \\
\hline & Others* & 3 & 0.5 \\
\hline \multirow[t]{10}{*}{ Ethnicity } & Bini & 331 & 51.7 \\
\hline & Igbo & 76 & 11.9 \\
\hline & Ishan & 59 & 9.2 \\
\hline & Yoruba & 39 & 6.1 \\
\hline & Urhobo & 35 & 5.5 \\
\hline & Owan & 18 & 2.8 \\
\hline & Delta Ibo & 16 & 2.5 \\
\hline & Afemai & 13 & 2.0 \\
\hline & Isoko & 10 & 1.6 \\
\hline & Others** & 43 & 6.7 \\
\hline
\end{tabular}

Table 2 shows that all caregivers were aware of immunization. Six hundred and seven (94.8\%) of the caregivers reported healthcare practitioners as their source of information, followed by $498(77.8 \%)$ who reported the media as their source of information, while 435 (68.0\%) indicated friends as their sources of information concerning immunization. The most popular vaccines were BCG and OPV and these were mentioned by $570(89.1 \%)$ of the caregivers, these were followed by HBV, which was reported by 478 (74.7\%), then DPT and PENTA mentioned by $452(70.6 \%)$ and $423(66.1 \%)$ mothers/caregivers respectively. 
Table 2: Mother's knowledge of routine immunization $\mathrm{N}=640$

\begin{tabular}{|c|c|c|c|}
\hline Variable & Distribution & Frequency & Percent \\
\hline \multirow{2}{*}{ Awareness of immunization } & Aware & 640 & 100.0 \\
\hline & No & 0 & 0 \\
\hline \multirow[t]{4}{*}{ Source of information* } & Healthcare practitioner & 607 & 94.8 \\
\hline & Media & 498 & 77.8 \\
\hline & Friends & 435 & 68.0 \\
\hline & Relatives & 344 & 53.8 \\
\hline \multirow[t]{8}{*}{ Vaccine mentioned* } & BCG & 570 & 89.1 \\
\hline & OPV & 570 & 89.1 \\
\hline & HBV & 478 & 74.7 \\
\hline & DPT & 452 & 70.6 \\
\hline & PENTA & 423 & 66.1 \\
\hline & Measles & 335 & 52.3 \\
\hline & PCV & 315 & 49.2 \\
\hline & Yellow fever & 315 & 49.2 \\
\hline \multirow[t]{3}{*}{ Number of vaccines mentioned } & 0 & 66 & 10.3 \\
\hline & $1-6$ & 259 & 40.5 \\
\hline & $\geq 7$ & 315 & 49.2 \\
\hline \multirow{4}{*}{$\begin{array}{l}\text { Knowledge of expected age of } \\
\text { completion of vaccination }\end{array}$} & $\overline{9}$ months & 610 & 95.3 \\
\hline & 12 months & 17 & 2.7 \\
\hline & 15 months & 6 & 0.9 \\
\hline & 18 months & 7 & 1.1 \\
\hline \multirow{4}{*}{$\begin{array}{l}\text { Knowledge of the purpose of } \\
\text { immunization }\end{array}$} & Prevents diseases & 585 & 91.4 \\
\hline & Makes child grow fast & 21 & 3.3 \\
\hline & Prolongs life & 18 & 2.8 \\
\hline & Makes child brilliant & 16 & 2.5 \\
\hline
\end{tabular}

*Mulitiple response

Findings from table 3 revealed 581 (90.8\%) children were vaccinated during the clinic visits of the survey while 59 $(9.2 \%)$ were not. One hundred and three $(16.1 \%)$ caregivers reported not getting vaccination for the index child at previous visits in the past. Of these, $73(70.9 \%)$ had one missed opportunity, $28(27.2 \%) 2$ while $2(1.9 \%)$ had three visits where they did not receive vaccination for which the child was eligible. Also, of this proportion $(n=103)$, PCV1 was the vaccine mostly implicated in missed opportunities [30 (29.1\%)] followed by PCV2 and PENTA2 [23 (22.3\%) and $13(12.6 \%)$ respectively]. Reasons given for missing vaccinations included non-availability of vaccines 69 $(67.0 \%)$, followed by lack of syringes and long waiting period [23 (22.3\%) and $22(21.4 \%)$ respectively].

Table 3: Missed opportunity for routine immunization in the child $\mathrm{N}=640$

\begin{tabular}{|c|c|c|c|}
\hline Variable & Distribution & Frequency & Percent \\
\hline \multirow[t]{2}{*}{ Ever had a missed opportunity for vaccination } & Yes & 103 & 16.1 \\
\hline & No & 537 & 83.9 \\
\hline \multirow[t]{3}{*}{ Total number of missed opportunities $(n=103)$} & 1 & 73 & 70.9 \\
\hline & 2 & 28 & 27.2 \\
\hline & 3 & 2 & 1.9 \\
\hline \multirow[t]{3}{*}{ Vaccine missed $(n=103)$} & PCV1 & 30 & 29.1 \\
\hline & PCV2 & 23 & 22.3 \\
\hline & PENTA2 & 13 & 12.6 \\
\hline
\end{tabular}

AJHSE 2(1) 


\begin{tabular}{llll} 
& PCV3 & 8 & 7.8 \\
& PENTA1 & 8 & 7.8 \\
& PENTA3 & 6 & 5.8 \\
& BCG & 6.9 \\
& Measles & 5 & 4.9 \\
& OPV1 & 5 & 1.9 \\
& Yellow fever & 2 & 1.9 \\
& OPV2 & 2 & 1.0 \\
Reasons for missing vaccination* $(\mathbf{n}=\mathbf{1 0 3})$ & No vaccines & 1 & 67.0 \\
& No syringes & 69 & 21.3 \\
& Long waiting period & 23 & 19.4 \\
& Do not have the time & 22 & 16.5 \\
& Not vaccination day & 20 & 16.5 \\
& Vaccination room was locked & 17 & 16.5 \\
& Person in charge not available & 17 & 12.6 \\
& Forgetfulness & 13 & 12.6 \\
& Healthcare worker did not ask & 13 & 8.7 \\
& Maltreatment by staff & 9 & 3.9 \\
& Child illness & 4 & 1.9 \\
\hline
\end{tabular}

*Multiple responses 581 children were vaccinated on the days of the survey

Two (40.0\%) children aged $18-23$ months had missed opportunities compared to 15 (11.5\%) of the 131 aged $6-11$ months. The association between the age of the index child and the prevalence of missed opportunities was statistically significant $(\mathrm{p}=0.013)$. There was no statistically significant association between the sex of the child and the prevalence of missed opportunities ( $\mathrm{p}=0.557)$. Eleven $(47.8 \%)$ of the 23 children delivered by TBAs had missed opportunities compared to $33(6.6 \%)$ of the 497 delivered in hospitals. The association between place of birth and prevalence of missed opportunities was statistically significant $(\mathrm{p}<0.001)$.

Two (66.7\%) of the 03 caregivers aged 50 - 59 years had children with missed opportunities compared to one $(14.3 \%)$ of the 07 aged less than 20 years. This association was not statistically significant $(p=0.064)$. There were no statistically significant associations between prevalence of missed opportunity and caregivers' marital status and prevalence of missed opportunities $(\mathrm{p}=0.704)$ and between the household sizes and the prevalence of missed opportunities ( $\mathrm{p}=0.752$ ). Fourteen $(16.5 \%)$ of those caregivers who had no formal education had missed opportunities compared to $3(11.1 \%)$ of those with tertiary level of education. This association was however not statistically significant $(\mathrm{p}=0.912)$. Twenty-seven $(16.8 \%)$ caregivers in SES class V had missed opportunities compared to 3 (13.6\%) of those in SES class II. None of those in SES class I had missed opportunities. This association was also not statistically significant $(\mathrm{p}=0.967)$. There was no statistically significant association between the caregivers' knowledge of immunization and the prevalence of missed opportunities $(\mathrm{p}=0.538)$. This is shown in table 4 
Table 4: Association between socio-demographic characteristics of caregiver's/ child and missed opportunity for vaccination $\mathrm{N}=640$

Missed opportunity

\begin{tabular}{|c|c|c|c|c|c|}
\hline \multirow[t]{2}{*}{ Variable } & \multirow[t]{2}{*}{ Distribution } & \multicolumn{2}{|c|}{ Ever missed a vaccine } & \multirow{2}{*}{$\begin{array}{l}\text { Test } \\
\text { statistic }\end{array}$} & \multirow[t]{2}{*}{$\mathrm{p}$ value } \\
\hline & & $\begin{array}{l}\text { Yes }(\mathrm{n}=103) \\
\mathrm{n}(\%)\end{array}$ & $\begin{array}{l}\text { No }(\mathrm{n}=537) \\
\mathrm{n}(\%)\end{array}$ & & \\
\hline \multirow[t]{3}{*}{ Child age (months) } & $0-5$ & $86(18.0)$ & $391(82.0)$ & \multirow[t]{3}{*}{$\chi^{2}=5.711$} & \multirow[t]{3}{*}{0.058} \\
\hline & $6-11$ & 15 (11.5) & $116(88.5)$ & & \\
\hline & $12-23$ & $2(6.3)$ & $30(93.7)$ & & \\
\hline \multirow[t]{2}{*}{ Sex of index child } & Male & $56(16.9)$ & $275(83.1)$ & \multirow[t]{2}{*}{$\chi^{2}=0.345$} & \multirow[t]{2}{*}{0.557} \\
\hline & Female & 47 (15.2) & $262(84.8)$ & & \\
\hline \multirow[t]{3}{*}{ Place of delivery } & Hospital & $33(6.6)$ & $464(93.4)$ & \multirow[t]{3}{*}{$\begin{array}{l}\chi^{2} \\
147.247\end{array}$} & $<0.001$ \\
\hline & Home & $59(49.2)$ & $61(50.8)$ & & \\
\hline & TBA & $11(47.8)$ & $12(52.2)$ & & \\
\hline \multirow{5}{*}{ Caregivers age (years) } & $<20$ & $1(14.3)$ & $6(85.7)$ & \multirow[t]{5}{*}{$\chi^{2}=6.849$} & \multirow[t]{5}{*}{0.144} \\
\hline & $20-29$ & 37 (15.9) & $195(84.1)$ & & \\
\hline & $30-39$ & 47 (14.2) & $285(85.8)$ & & \\
\hline & $40-59$ & $17(27.4)$ & $45(72.6)$ & & \\
\hline & $\geq 60$ & $1(14.3)$ & $6(85.7)$ & & \\
\hline \multirow[t]{2}{*}{ Marital status } & Unmarried & $3(12.0)$ & $22(88.0)$ & \multirow[t]{2}{*}{$\chi^{2}=0.322$} & \multirow[t]{2}{*}{0.570} \\
\hline & Married & $100(16.3)$ & $515(83.7)$ & & \\
\hline \multirow[t]{3}{*}{ Household size } & $\leq 4$ & $40(15.2)$ & $224(84.8)$ & \multirow[t]{3}{*}{$\chi^{2}=0.569$} & \multirow[t]{3}{*}{0.752} \\
\hline & $5-8$ & $59(16.5)$ & $298(83.5)$ & & \\
\hline & $\geq 9$ & $4(21.1)$ & 15 (78.9) & & \\
\hline \multirow[t]{4}{*}{$\begin{array}{l}\text { Caregivers level of } \\
\text { education }\end{array}$} & No formal education & $14(16.5)$ & $71(83.5)$ & \multirow[t]{4}{*}{$\chi^{2}=0.503$} & \multirow[t]{4}{*}{0.912} \\
\hline & Primary & 60 (16.4) & 306 (83.6) & & \\
\hline & Secondary & $26(16.0)$ & $136(84.0)$ & & \\
\hline & Tertiary & $3(11.1)$ & 24 (88.9) & & \\
\hline \multirow[t]{5}{*}{ Socioeconomic status } & Class I & $0(0.0)$ & $2(100.0)$ & \multirow[t]{5}{*}{$\begin{array}{l}\text { Fishers } \\
\text { exact } \\
0.527\end{array}$} & \multirow[t]{5}{*}{0.967} \\
\hline & Class II & 3 (13.6) & $19(86.4)$ & & \\
\hline & Class III & $19(14.6)$ & $111(85.4)$ & & \\
\hline & Class IV & $54(16.6)$ & $271(83.4)$ & & \\
\hline & Class V & $27(16.8)$ & 134 (83.2) & & \\
\hline \multirow{3}{*}{$\begin{array}{l}\text { Knowledge } \\
\text { immunization }\end{array}$} & Poor & $36(14.6)$ & $211(85.4)$ & \multirow[t]{3}{*}{$\chi^{2}=1.240$} & 0.538 \\
\hline & Fair & $16(19.8)$ & $65(80.2)$ & & \\
\hline & Good & $51(16.3)$ & $261(83.7)$ & & \\
\hline
\end{tabular}

Statistically Significant

Children aged 4 months, or more were 7 times more likely to have missed opportunities for vaccination compared to their younger counterparts. The association between age and missed opportunity for immunization was statistically significant $(\mathrm{p}<0.001)$. Children born outside hospitals were 12 times more likely to have missed opportunities for vaccination compared to those delivered in hospitals. The association between place of delivery and missed opportunity for immunization was also statistically significant $(\mathrm{p}<0.001)$. (Table 5) 
Table 5: Predictors of missed opportunities among the index children

\begin{tabular}{|c|c|c|c|c|c|c|}
\hline \multirow[t]{2}{*}{ Predictors } & \multirow[t]{2}{*}{ Distribution } & \multirow{2}{*}{\multicolumn{2}{|c|}{$\begin{array}{l}\text { B (regression p-value } \\
\text { coefficient) }\end{array}$}} & \multirow[t]{2}{*}{ Odd Ratio } & \multicolumn{2}{|c|}{ 95\% C.I. for Odd ratio } \\
\hline & & & & & Lower & Upper \\
\hline \multirow{2}{*}{ Child age (months) } & $\leq 3$ months $*$ & & & & & \\
\hline & $\geq 4$ months & 1.888 & $<0.001$ & 6.604 & 3.805 & 11.465 \\
\hline \multirow[t]{2}{*}{ Delivery place } & Hospitals* & 1 & & & & \\
\hline & Others & 2.497 & $<0.001$ & 12.150 & 7.215 & 20.462 \\
\hline \multirow[t]{2}{*}{ Caregivers age (years) } & $<40$ & 0.204 & 0.653 & 1.226 & 0.504 & 2.981 \\
\hline & $\geq 40^{*}$ & 1 & & & & \\
\hline \multirow[t]{2}{*}{ Marital status } & Ever married & 0.549 & 0.490 & 1.731 & 0.364 & 8.232 \\
\hline & Never married* & 1 & & & & \\
\hline \multirow[t]{2}{*}{ Household size } & $\leq 4$ & 0.208 & 0.450 & 1.231 & 0.718 & 2.110 \\
\hline & $>4 *$ & 1 & & & & \\
\hline \multirow{2}{*}{ Caregivers level of education } & Primary or less & 0.735 & 0.074 & 2.086 & 0.931 & 4.674 \\
\hline & Secondary/tertiary* & 1 & & & & \\
\hline \multirow[t]{2}{*}{ Employment } & Yes & 0.127 & 0.754 & 1.135 & 0.513 & 2.513 \\
\hline & No* & 1 & & & & \\
\hline \multirow[t]{3}{*}{ Socioeconomic status } & Classes I - III* & & & & & \\
\hline & Classes IV and V & 0.667 & 0.139 & 1.949 & 0.804 & 4.720 \\
\hline & Constant & -4.690 & 0.000 & 0.009 & & \\
\hline
\end{tabular}

*Reference category; Coefficient of determination $\left(\mathrm{R}^{2}\right)=24.2 \%-41.2 \%$; Significant; C. I = confidence interval

\section{DISCUSSION}

The national immunization policy recommends that all vaccines be made available at immunization centres every day, but this was not the case as observed in this study. About a tenth of the index children surveyed at the health facilities were not vaccinated. This was due to non-availability of immunization services, facilities restriction of administration of certain antigens to certain days and limitation of the number of persons attended to during an immunization session.

Similar findings have also been reported in a Nigerian study (Fatiregun et al.,2014) where about a tenth of the children were not vaccinated due non-availability of vaccines. The implications of frequent non-availability and stock outs of vaccines in PHCs are delayed vaccination, missed opportunities and incomplete immunization of children. Most outstanding reason for missing scheduled immunization in this study was lack of vaccine, this was also the most reported reason given for missed opportunity in studies carried out in Benin City (Sadoh and Eregie, 2011) and Ibadan (Brown et al., 2015) The lack of vaccines may be due to the fact that supplies were not available to the health facilities occasioned by logistic problems (transportation, poor distribution networks) and reduced motivation on the part of the health workers in the PHCs who may be owed salaries. Other reasons would include inability of the health workers to properly forecast the vaccine needs of the health centre, since there was no report of vaccine shortage in the country during the period of the study as long waiting time and visit on the wrong day were the other reasons given for missed opportunity for immunization in this study

The prevalence of missed opportunity in this study was $16.1 \%$, and this finding is similar to that noted in a study from Anambra state, Nigeria where missed opportunity for immunization was given sixteen percent, (Rima, 2011) the sixteen percent prevalence noted in this study is low compared to twenty eight and thirty nine percent 
reported in studies carried in Benin City (Onyiruika, 2005) and Calabar (Anah et al., 2006)The low rate of missed opportunity noted in this study, may be an indication of the improved knowledge and quality of immunization services offered at the PHCs, which the mothers perceived as good in the study locale.

More than a quarter of the index children missed vaccination twice and PCV1 was the vaccine mostly implicated followed by PCV2 and PENTA2. This observation is in contrast to findings contained in a study from Anambra, State in 2012, (Adogu et al., 2012) where the most common vaccines missed were BCG, OPV0, OPV1, HBV1 and DPT1 and Calabar in 2006 were measles vaccine given at nine months of age was the commonest vaccine missed. ${ }^{22}$ The variations in trend between this study and others could be due to the differences in the years the studies were carried out as the vaccines missed in this study are the newest additions to the immunization schedule. The low rate of missed opportunities for immunization in these PHCs may be indication of effective routine immunization services. This could be further improved upon by exploiting visits for curative care to fully immunize the children chances provided and increasing the immunization coverage of the vaccines. There may also be need for health workers in curative health care centres to be more involved in checking the vaccination cards and sending incompletely vaccinated children to immunization sessions of the health facilities. Involvement of community and religious leaders in routine immunization may also be required to scale up immunization coverage by supplementing the scarce human resources and optimising co-ordination of different activities at fixed health stations and in mobile teams.

Socio-demographic factors that significantly influenced missed opportunity for immunization in this study included the level of education of the mother/caregiver, age, and place of delivery of the child. Children aged less than 4 months were found to be completely immunized for age compared to those aged 4 months and above. This finding is consistent with that found in a study conducted in Ethiopia, where the child's age was a strong predictor for incomplete immunization. (Yenit at al., 2015) It could be stipulated that older children run a greater risk of becoming unvaccinated because their caregivers fail in complying with multidose vaccine series they increase in age. They therefore tend to fall behind on receipt of vaccines that are administered in the second half of infancy. In this study, a significant proportion of children aged 2 months had missed opportunities for vaccine doses that they should have received. The inability to receive follows up doses of such vaccines that were found in older infants. Missed opportunities worsen the multi dose vaccines, such pentavalent vaccine compared to the incidence of missed opportunities in single-dose vaccines. The greater incidence of missed opportunity with multi-dose vaccines may suggest that parents and healthcare professionals perceive such immunization as less important for older children. This is corroborated by findings in some studies that have shown a greater risk for non-vaccination and missed opportunities among older children, presumably due to the complacency and inadequate attention paid to vaccination in this age group of the children and complacency (Adebayo et al., 2012).

\section{CONCLUSION}

Prevalence of missed opportunities which was $16.1 \%$ recorded in this study was high, while age and place of delivery were predictors of missed opportunity for vaccination. It is therefore important that mothers be properly advised on the steps they need to take if they travelled to other locations, loose vaccination cards, children who had side effects after immunization, or missed appointment for any reason and also awareness should be raised to empower women 
and increase spouse' involvement in child immunization to improve immunization coverage of the antigens through regular campaigns by mass media and immunization health talks.

\section{REFERENCES}

Abdulraheem, I, Onajole, A.T, Jimoh, A. Oladipo, A.R. (2011). Reasons for incomplete vaccination and factors for missed opportunities among rural children. Journal of Public Health and Epidemiology. 3 (4):194-203.

Adebayo, B.E, Oladokun, R.E, Akinbami, F.O. (2012). Immunization coverage in a rural community in South-eastern Nigeria. Journal of Vaccines and Vaccination. 3:143. Doi;10.4172/2157-7560.1000143.

Adogu, P.U, Nnebue, C.K, Ebenebe, U.E, Ezechukwu, C.C (2012). Caregivers' satisfaction and supervision of primary health care services in Nnewi, Nigeria. Nigerian Journal of Paediatrics. 39(4):179 -184. doi:10.4314/njp.v39i4.6

Adedire, E.B, Ajayi, I, Fawole,I.O, Ajumobi, O, Kassasa ,S. Wassawa, P. (2016). Immunization coverage and its determinants among children aged 12-23 months in Atakumosa-West district Osun State Nigeria. BioMed Central Public Health. 16:905.

Anah, M.U, Etuk, I.S, Udo, J.J. (2006). Opportunistic immunization with in-patient programme: eliminating a missed opportunity in Calabar, Nigeria. Annuals of African Medicine.5(4):188-191.

Brown, V.B, Oluwatosin. A, Ogundeji. M.O. (2015). Experiences, perceptions, and preferences of mothers towards childhood immunization reminder/recall in Ibadan, Nigeria: a cross-sectional study. The Pan African Medical Journal. 20:243. Doi: 10.11604/ pamj.2015.20.243.6019.

Cochrane, W.G. Sampling Techniques, 3rd Edition. New York: John Wiley and Son 1977.

Ekure, E.N., Esezobor, C.I, Balogun, M.R, Mukhtar-Yola. M, Ojo,O.O, Emodi, IJ. (2013). Community knowledge, attitude, and practice of childhood immunization in Southwest Nigeria. Nigerian Journal of Paediatrics.40 (2):106 -111.

Erilesli, S.I. Technical report: Monitoring and supervision of first national immunisation days in Jigawa State, Nigeria. UNICEF. WHO and FMOH offices in Lagos, Nigeria? 1998.

Fatiregun, A.A, Alonge, T.O, Rukewe, A. Etukire, E. Chidinma, U. Adejugbagbe, A.M. (2014) An assessment report on an immunization clinic located in a tertiary institution in Ibadan. Nigerian Journal of Paediatrics. 41(3):163-169

Favin, M. steinglass, R. Fields, R. Banerje, K. sahney, M. (2012). Why children are not vaccinated: a review of the grey literature. International health. 4(4): 229 - 238.

Federal Ministry of Health. National immunization policy and standard of practice. Abuja: Federal Ministry of Health, 2009:16.

Ireye, F. Bassey, E.B. Komakech, W. Okocha-Ejeko, A. Ali, D. Agwai. S.I. (2017). Determination of routine immunization coverage using estimated and survey generated population in Orhiomwon Local Government Area in South-South Nigeria. Journal of infectious disease and medicine. 2 :112.

Matua, M.K, Kimani-murage, E, Ngomi, N. Ravn, .H, Mwaniki, P, Echoka, E. (2016). Fully immunized child; 
coverage, timing and sequencing of routine immunization in urban poor settlement in Nairobi. Kenya Tropical Medicine and Health. 44 (13):1-12.

Onyiriuka, A.N. (2005) Vaccination default among children attending a static immunization clinic in Benin City. Nigeria. Journal of Medicine and Biomedical Research. 4(1):71-77.

Ronveaux, O. Rickert, D. Handler, S. Groom, H. Lloyd, J. Bchir, A. (2005) The immunization data audit. Verifying the quality and consistency of immunization monitoring systems. Bulletin of the world Health Organisation. 83 (7):503-510.

Sadoh, A.E, Eregie, O.C. (2009) Timeliness and Completion Rate of Immunization among Nigerian children attending a clinic-based Immunization service. Journal of Health Population and Nutitionr. 27(3):391-395

Sato, P. Expanded Programme on Immunization protocol for the assessment of missed opportunity for immunization. 1988. WHO/EPI/GEN 88.6:7-9

Scott, S. Odutola, A, Mackenzie, G. Fulford, T. Afolabi, M. O, Jallow, Y.L.Jasseh, M .(2014). Coverage and timing of children vaccination: An evaluation of the Expanded Programme on Immunization in the Gambia. PloS ONE. 9(9):1-9.

Sodha, S.V, Dietz, V. (2015). Strengthening routine immunization systems to improve global vaccination coverage. British Medical Bulletin.; 113 (1):5-14.

Tagbo, B.N, Eke, C.B, Omotowo, B.I, Onwasigwe, C.N, Onyeka, E.B Mildred UO. (2014) Vaccination coverage and its determinants in Children aged 11 - 23 months in an urban district of Nigeria. World Journal of Vaccines. (4):175-183.

Tagbo, B.N, Uleanya, N.D, Nwokoye, I.C, Eze, J.C, Omotowo, I.B. (2012) Mothers' knowledge, perception, and practice of childhood immunization in Enugu. Nigerian Journal of Paediatrics. 39 (3):90-96.

Udonwa, N, Gyuse, A.N, Etokidem, A.J, Ogaji, D.S (2010). Client views, perception, and satisfaction with immunization services at Primary Health Care Facilities in Calabar south-south. Asian Pacific Journal of Tropical Medicine. 3(4)298-301. Doi.org/10.1016/s1995-7645(10)60073-9

Yenit, M.K, Assegid, S, Abrha, H. (2015) Factors associated with incomplete childhood vaccination among children 12-23 Months of Age in Machakel Woreda, East Gojjam Zone: A Case Control Study. Journal of Pregnancy and Child Health.; 2:180. Doi: 10.4172/2376-127x.1000180. 